Article

\title{
Impacts of LEDs in the Red Spectrum on the Germination, Early Seedling Growth and Antioxidant Metabolism of Pea (Pisum sativum L.) and Melon (Cucumis melo L.)
}

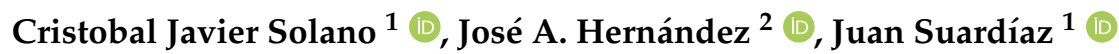 \\ and Gregorio Barba-Espín 2,* (D) \\ 1 División of Innovation in Telematic Systems and Electronic Technology (DINTEL), Technical University of \\ Cartagena, Campus Muralla del Mar, s/n. E-30202 Cartagena, Spain; \\ cristobaljavi.solano@murciaeduca.es (C.J.S.); juan.suardiaz@upct.es (J.S.) \\ 2 Department of Plant Breeding, Fruit Tree Biotechnology Group, CEBAS-CSIC, Campus Universitario de \\ Espinardo, P.O. Box 164, E-30100 Murcia, Spain; jahernan@cebas.csic.es \\ * Correspondence: gbespin@cebas.csic.es
}

Received: 21 April 2020; Accepted: 1 June 2020; Published: 5 June 2020

\begin{abstract}
Background: In recent years, the use of light emitting diodes (LEDs) for plant production purposes has expanded. However, LEDs' effect on seed germination and early seedling growth has been scarcely documented. (2) Methods: In this work, the effect of monochromatic red light (RL, $100 \mu \mathrm{mol} \mathrm{m}^{-2} \mathrm{~s}^{-1}$ ) for up to $60 \mathrm{~min}$ applied to seeds of pea and melon was analyzed in terms of seedling growth and antioxidant enzymes levels. An experimental LED chamber coupled to an electronic control system was developed for this purpose. (3) Results: RL did not alter the germination rate, but significantly improved the early seedling growth. Pea and melon seedlings showed the highest increase in fresh weight and length upon 15 min RL treatment of the seeds, whereas longer exposure times decreased seedling growth. Interestingly, RL favored the development of secondary roots in both species, which could favor the nutrition and water uptake by the seedling. The ability of the seedlings to respond to a hypothetical LED irradiance-induced oxidative stress was reflected differently on the antioxidant system of pea and melon. (4) Conclusions: These findings can be relevant for designing seed priming treatments to improve plant vigor, thus enhancing the productivity of important crop plants.
\end{abstract}

Keywords: antioxidant enzymes; experimental light chamber; germination; light-emitting diode (LED); phytochrome; red light; seedling growth

\section{Introduction}

Seed germination is a complex biological process determined by genetic, endogenous and environmental factors [1,2]. Among them, light plays a key role in the adjustment of plant populations to their habitat [3]. Light induction of germination is exclusively mediated by phytochrome $B$ and other phytochromes that perceive the red $(600-700 \mathrm{~nm})$ to far-red $(700-800 \mathrm{~nm})$ ratio [4], being maximally induced by a saturating pulse of monochromatic red light (RL) [5], in which the photoreceptor pigment is activated as a switch between $640 \mathrm{~nm}$ and $670 \mathrm{~nm}$. The photoreversible nature of the phytochrome molecule explains its molecular switch behavior, as demonstrated in different studies conducted in different plants species, including lettuce, Paulownia and Arabidopsis [6-8]. In brief, the inactive, red-adsorbing phytochrome form becomes active by RL irradiation, which turns again into the inactive form by far-red light [9]. This was first shown on lettuce seeds, where pulses of RL 
triggered germination, while pulses of far-red light inhibited it [10]. Moreover, the effect of short RL exposure on the germination of seeds that exhibit photodormancy, such as that of some varieties of lettuce, pepper grass (Lepidium virginianum L.) and Arabidopsis [11,12], is well known. The amount of chlorophyll that covers the seed embryo is important to determine whether a seed of a given species will present photodormancy [13]. In general, embryos that during maturation are covered by maternal tissues that contain high levels of chlorophyll will require light for the germination process, while those that are covered by maternal tissue that contains little or no chlorophyll will not need light to germinate [14]. However, there are exceptions—such as pea and bean seeds, which are capable of germinating in darkness.

Priming techniques have been widely used to improve speed and uniformity of radicle emergence, which result in improved productivity in different plant species. In melon, osmopriming is a common strategy for seed priming. In this regard, the priming of melon seeds with $\mathrm{KNO}_{3}, \mathrm{KH}_{2} \mathrm{PO}_{4}$ plus $\mathrm{KNO}_{3}$, $\mathrm{NaCl}$, mannitol and polyethylene glycol improved the germination process [15-18]. However, the effect of monochromatic RL alone on melon germination and plant growth has not been tested. Light is one of the key environmental factors that affect the development of the plant. In this sense, it has been described that both red and blue $(470 \mathrm{~nm})$ light can affect the architecture of the plant [19-22]. Recently, it has been reported that melon plants treated with blue light or the combination red-blue light (3:1) increased the tolerance to powdery mildew, whereas the combination red-blue light increased plant growth [23]. Regarding pea seeds, recent works described that $\mathrm{H}_{2} \mathrm{O}_{2}$-priming increased the germination rate as well as the early seedling growth [10], whereas $\mathrm{KNO}_{3}$ treatments modulated the levels of the plant hormones $\mathrm{GA}_{4}$ and $\mathrm{ABA}$, this response being correlated with an increase in the biomass of pea seedlings [24].

In recent years, the use of solid state lighting (SSL) technology based on light emitting diodes (LEDs) has spread for plant production purposes, since it allows a tight control of waveband emission and light intensity with low energy consumption [25]. Most of the research concerning the effect of LED technology on plant growth and morphogenesis has been carried out under in vitro conditions [26]. However, the effect of LED lighting on seed germination and early seedling growth under ex vitro conditions has been scarcely documented. LED irradiation significantly alters the cell redox homeostasis and reactive oxygen species (ROS) content, which induces the activation of the antioxidative metabolism and ROS-scavenging enzymes to alleviate ROS-mediated stress and restore cell redox balance [26-28].

In this work, pea and melon seeds were subjected to short-term RL irradiation from LED luminaires, to test its effect on the germination, seedling growth and antioxidant metabolism of the seedlings. For this purpose, an experimental light chamber was designed to tightly control and register the exposure time and environmental conditions. This represents the first study reporting a priming effect of monochromatic RL on the early growth of pea and melon, and provides input on the involvement of the antioxidant enzymes on the stimulated growth of the seedlings. Moreover, it contributes towards the applicability of LED technology on the germination process.

\section{Materials and Methods}

\subsection{Experimental Chamber and Lighting Technology}

A modulable spectrum plant experimental chamber (MSPEC) (Figure 1) was designed, of which dimensions were $500 \mathrm{~mm}$ wide $\times 350 \mathrm{~mm}$ high $\times 350 \mathrm{~mm}$ deep, with a surface area of $0.175 \mathrm{~m}^{2}$. It had a profile structure made of galvanized steel sheet and an outer chassis in cardboard. The inner walls were coated with a thin sheet of highly reflective aluminum that performed the function of reflecting the light beams coming from the luminaires. Up to ten SSL-LED luminaires emitting in the spectrum between $650 \mathrm{~nm}$ and $670 \mathrm{~nm}$ (OSLON SSL, OSRAM, Munich, Germany) were mounted on SMD LED chips (OSRAM) and coupled to optical lens of $120^{\circ}$ to focus light. Subsequently, LEDs were placed in two rows at a height of $250 \mathrm{~mm}$ in the central part of the upper surface, mounted on a sheet of 
aluminum $(400 \times 300 \times 5 \mathrm{~mm})$ grooved on the back to improve heat dissipation from the electronics. Distance between individual LEDs was $25 \mathrm{~mm}$.

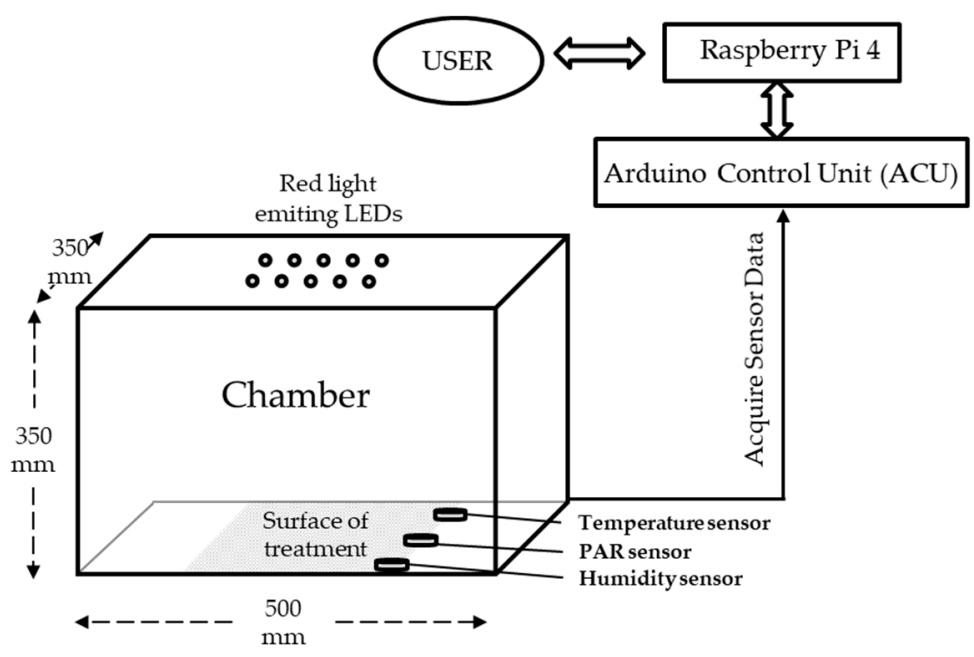

Figure 1. Dimensions, main components and operation workflow of the modulable spectrum plant experimental chamber.

Sensors for monitoring temperature, relative humidity (RH) (DHT-22 AM2302, Aosong Electronics Co. Guangzhou, China), luminance (Lux; TSL-2561, Texas Advanced Optoelectronic Solutions Inc., Plano, TX, USA) and active photosynthetic radiation ( $\left.\mu \mathrm{mol} \mathrm{m}^{-2} \mathrm{~s}^{-1}, \mathrm{PAR}\right)$ in the range $400-700 \mathrm{~nm}$ (Smart Quantum Sensor SQ-420, Apogee Instruments, Logan, UT, USA) were used to measure along the surface of the MSPEC, and connected to an Arduino Control Unit (ACU) (BCMI Corp., Bellingham, WA, USA) located in an external control box. The ACU transmitted information to the user through a Raspberry Pi device, which processed and registered the information (Figure 1). The Table 1 shows the electrical power and maximum light intensity achieved for 1,2,5 and 10 LEDs.

Table 1. Energy consumption (W), maximum values of illuminance (Lux) and photosynthetic active radiation (PAR, $\mu \mathrm{mol} \mathrm{m} \mathrm{m}^{-2} \mathrm{~s}^{-1}$ ) in function of the number of LEDs.

\begin{tabular}{cccc}
\hline $\mathbf{n}^{\circ} \mathbf{L E D}$ & PAR $\left(\boldsymbol{\mu \mathbf { m o l }} \mathbf{~}^{-\mathbf{2}} \mathbf{s}^{-\mathbf{1}}\right)$ & Luminance (Lux) & Electrical Power $(\mathbf{W})$ \\
\hline 1 & 10.1 & 118 & 0.71 \\
2 & 22.4 & 256 & 1.42 \\
5 & 55 & 624 & 3.58 \\
10 & 110 & 1283 & 7.17 \\
\hline
\end{tabular}

\subsection{Red Light Treatment of Seeds in the MSPEC}

Seeds of the hybrid melon variety 'Edecos' (Seminis Vegetable Seeds Iberica, S.A., Murcia, Spain) and of garden pea (Pisum sativum L. cv. Alaska, Ed Hume Seeds Store, Puyallup, WA, USA) were utilized. Pea seeds were subjected to water inhibition for $12 \mathrm{~h}$ prior to the RL treatment. Seeds were placed in $15 \mathrm{~cm}$ Petri dishes ( 15 seeds per dish) with three layers of filter paper moistened with $\mathrm{dH}_{2} \mathrm{O}$ (6 mL). Melon seeds were subjected to $100 \mu \mathrm{mol} \mathrm{m}^{-2} \mathrm{~s}^{-1} \mathrm{RL}$ for $0,5,10,15,30$ or $60 \mathrm{~min}$. Pea seeds were subjected to $100 \mu \mathrm{mol} \mathrm{m}^{-2} \mathrm{~s}^{-1} \mathrm{RL}$ for $0,5,15,30$ or $60 \mathrm{~min}$. For each light application, four Petri dishes were treated at a time. After each treatment, the Petri dish was wrapped with aluminum foil to prevent additional light treatment and incubated at $25^{\circ} \mathrm{C}$ for 3 days in the dark (Cooled Incubator MIR-153 Sanyo, Osaka, Japan). After the incubation period, the length and fresh weight (FW) of the seedlings were measured individually, resulting in 45 experimental units per variable. Experiments were conducted at least twice with similar results. 


\subsection{Sample Preparation and Enzyme Activities Determination}

The 15 seedlings from each plate were pooled to obtain an adequate weight for the enzyme extraction and analysis, resulting in the use of 3 experimental units per treatment. Samples were subjected to enzyme extraction according to [29,30]. In brief, samples were homogenized in $50 \mathrm{mM}$ Tris-acetate containing $20 \mathrm{mM}$ sodium ascorbate, $0.1 \mathrm{mM}$ EDTA, $2 \mathrm{mM}$ cysteine and $0.2 \%(v / v)$ Triton $\mathrm{X}-100(\mathrm{pH} 6.0)(1: 2, w / v)$. All operations were performed at $4^{\circ} \mathrm{C}$. The extracts were filtered through two layers of nylon cloth and centrifuged at 10,000 $\times g$ for $15 \mathrm{~min}$. The resulting supernatant was filtered on Sephadex NAP-5 columns (GE Healthcare, Chicago, IL, USA) equilibrated with $50 \mathrm{mM}$ Tris-acetate, following manufacturer's instructions. The protein concentration of the resulting purified extracts was determined according to [31]. Ascorbate peroxidase (APX, EC1.11.1.11), monodehydroascorbate reductase (MDHAR, EC1.6.5.4), glutathione reductase (GR, EC1.6.4.2), superoxide dismutase (SOD, EC1.15.1.1), dehydroascorbate reductase (DHAR, EC1.8.5.1) and peroxidase (POX, EC.1.11.1.7) activities were determined in the extracts following protocols described in our laboratory $[32,33]$. Analyses were conducted twice with similar results.

\subsection{Statitical Analyses}

Analyses for the growth measurements were done with data from 45 experimental units (individual seedlings). Analyses for the antioxidant enzymes activities were done with three experimental units, each one consisting of the pool of 15 seedlings from a Petri dish. Data were subjected to statistical analysis using the SPSS 20.0 software (SPSS Inc., 2002, Chicago, IL, USA). Treatments were compared using one-way analysis of variance (ANOVA) followed by a Tukey post-hoc test $(p \leq 0.05)$.

\section{Results}

In the present study, a prototype of modulable spectrum plant experimental chamber (MSPEC) was developed for testing the effect of specific RL doses on the germination and early growth of melon and pea seeds. To visualize the light distribution pattern along the chamber, photosynthetic active radiation (PAR) was measured at different coordinates on the work surface of the MSPEC for 5 (Figure 2a) and 10 LEDs (Figure 2b). Acquired data were processed with a Matlab script (Mathworks, Natick, MA, USA), from which a graphical representation of PAR distribution values was derived (Figure 2). Ten LEDs were chosen for germination tests as they provided PAR values of around $100 \mu \mathrm{mol} \mathrm{m}{ }^{-2} \mathrm{~s}^{-1}$ in most of the surface, which allowed the arrangement of up to four Petri dishes on it. Sensors for temperature and humidity provided data ranging from 23 to $25{ }^{\circ} \mathrm{C}$ and from 55 to $60 \%$ $\mathrm{RH}$, respectively, on all the work area (data not shown).

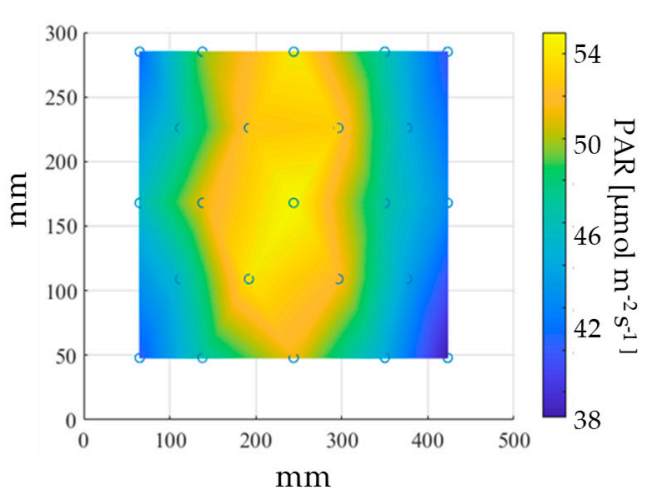

(a)

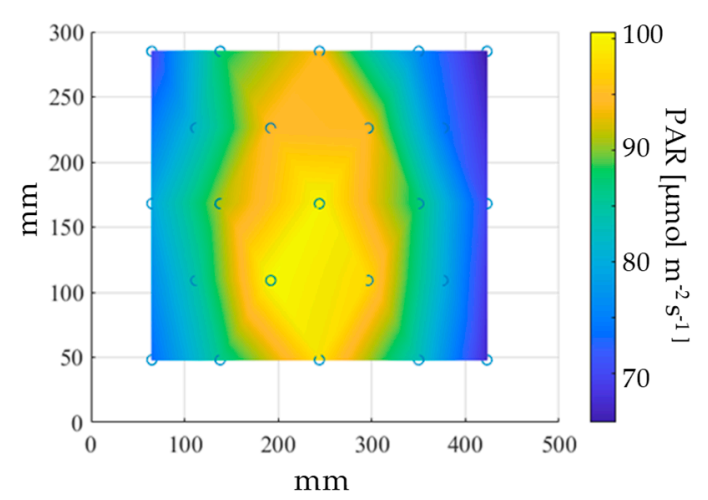

(b)

Figure 2. Spatial distribution of the photosynthetically active radiation (PAR, $\mu \mathrm{mol} \mathrm{m} \mathrm{m}^{-2} \mathrm{~s}^{-1}$ ) on the modulable spectrum plant experimental chamber inner surface for a 5- (a) and 10-LEDs (b) luminaires. Blue circular shapes indicate the coordinates from which measurements were taken. 
Both melon and pea seeds were subjected to $100 \mu \mathrm{mol} \mathrm{m} \mathrm{m}^{-2} \mathrm{~s}^{-1}$ PAR ( 0 to $60 \mathrm{~min}$ ) and FW and length registered three days after the light treatment. Regarding the germination percentages, no differences were found between untreated and treated seeds of both plant species, invariably showing values of 90-93\% (data not shown). However, the RL treatment increased the biomass production. Melon seedlings exposed to $15 \mathrm{~min}$ RL displayed FW values significantly higher than those of untreated (44\%), $30 \mathrm{~min}$ $(46 \%)$ and $60 \mathrm{~min}$-treated seeds $(39 \%)(p=0.002)$ (Figure 3a). On the other hand, $15 \mathrm{~min}$ RL treatment increased significantly the length of the seedlings with respect to control (33\%) and 30 min-treated seeds $(29 \%)(p=0.003)$ (Figure 3b). Interestingly, RL favored the development of secondary roots, this effect being more evident in melon seedlings after $15 \mathrm{~min}$ of light exposure (Figure 3c).

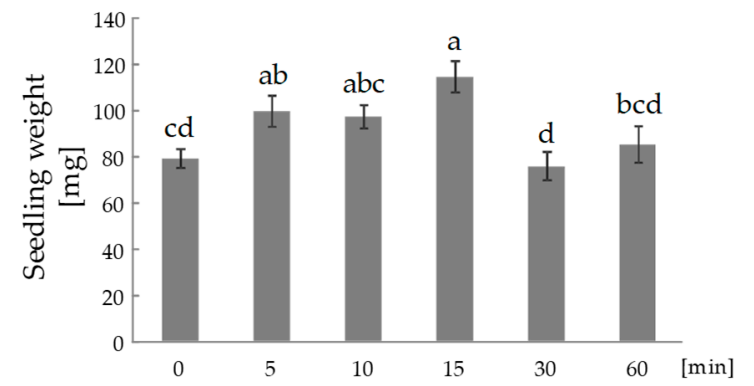

(a)

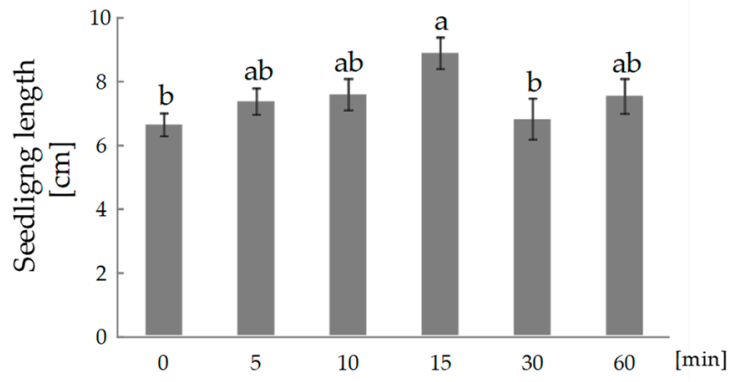

(b)
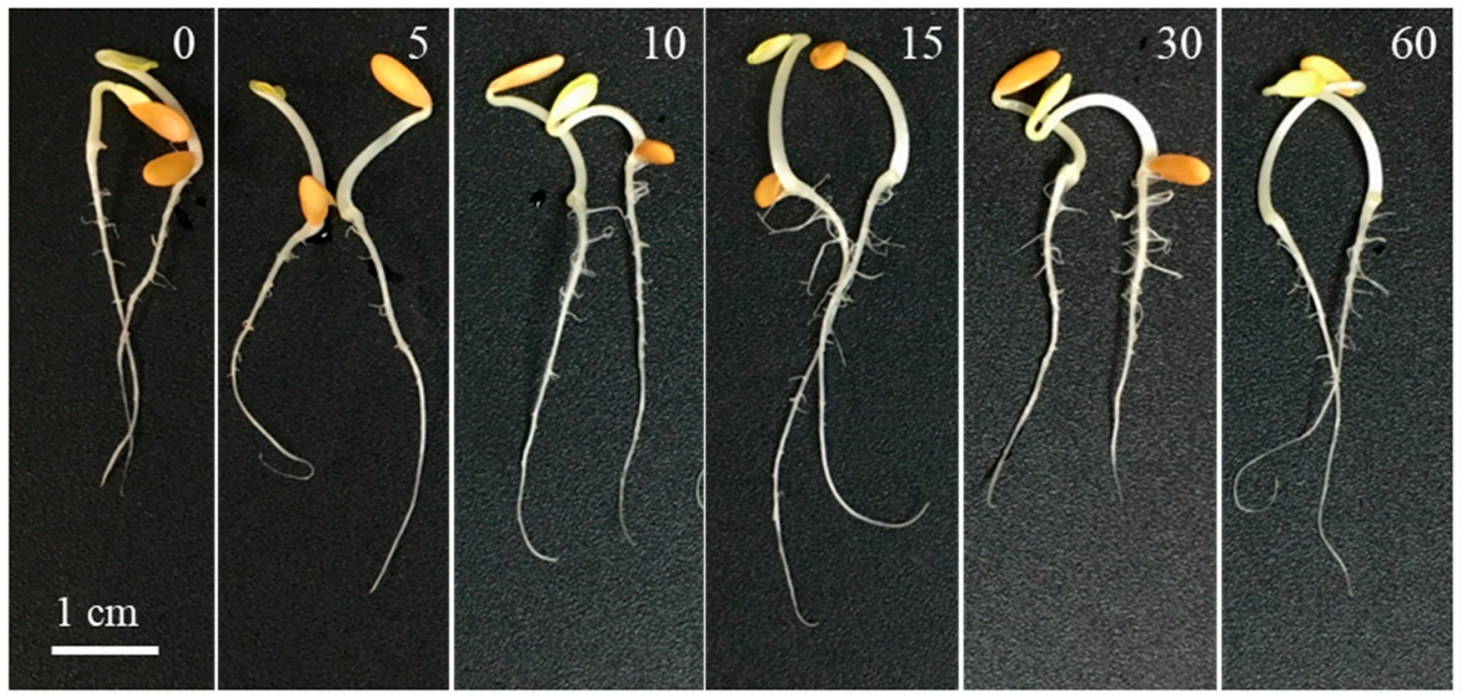

(c)

Figure 3. Effect of red light exposure $\left(100 \mu \mathrm{mol} \mathrm{m} \mathrm{m}^{-2} \mathrm{~s}^{-1}\right)(0-60 \mathrm{~min})$ of melon seeds on the fresh weight (a), length (b) and overall appearance (c) of 3-day-old seedlings. Data represent the mean \pm SE from 45 measurements. Different letters indicate significant differences according to Tukey's test $(p \leq 0.05)$.

Pea seeds (cv. Alaska) responded similarly to $100 \mu \mathrm{mol} \mathrm{m}{ }^{-2} \mathrm{~s}^{-1}$ PAR, showing a peak in FW (54\%) on 15 min-treated seeds with respect to untreated seeds, whereas a 60 min exposure time decreased seedling weight significantly $(p=0.002)$ (Figure $4 a)$. On the other hand, no significant differences were found in seedling length in response to RL ( $p=0.126$ ) (Figure $4 \mathrm{~b})$. Moreover, RL favored the development of secondary roots, especially after $15 \mathrm{~min}$ of light exposure (Figure 5). Moreover, the growth of pea seedlings treated with 15 min RL was monitored until the adult plant stage in hydroponic culture, to test whether the priming effect of RL was maintained over time. Here, the aerial biomass of 3- to 6-week-old treated plants was 30-50\% higher than that of untreated plants (data not shown), which was visually patent in, for example, 3-week-old plants (Figure 6). 


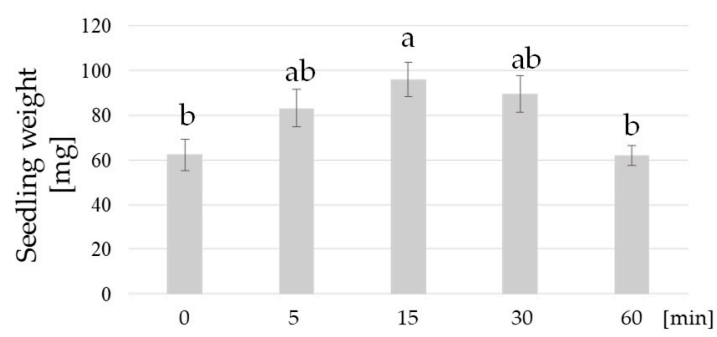

(a)
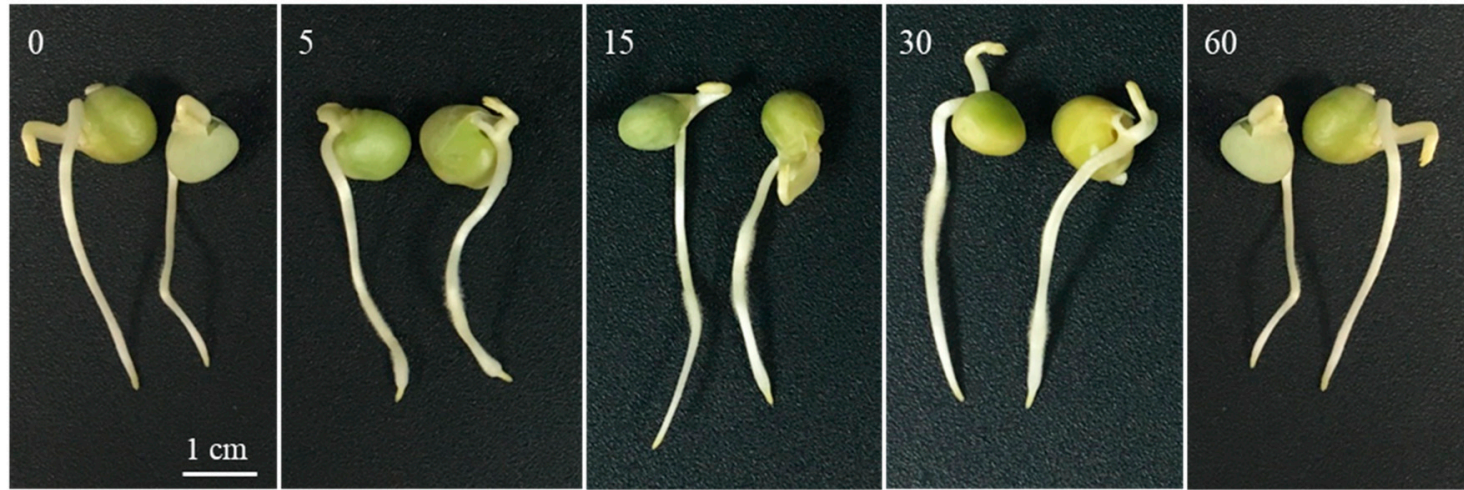

(c)

Figure 4. Effect of red light exposure $\left(100 \mu \mathrm{mol} \mathrm{m}{ }^{-2} \mathrm{~s}^{-1}\right)(0-60 \mathrm{~min})$ of pea seeds on the fresh weight (a), length (b) and overall appearance (c) of 3-day-old seedlings. Data represent the mean \pm SE from 45 measurements. Different letters indicate significant differences according to Tukey's test $(p \leq 0.05)$.
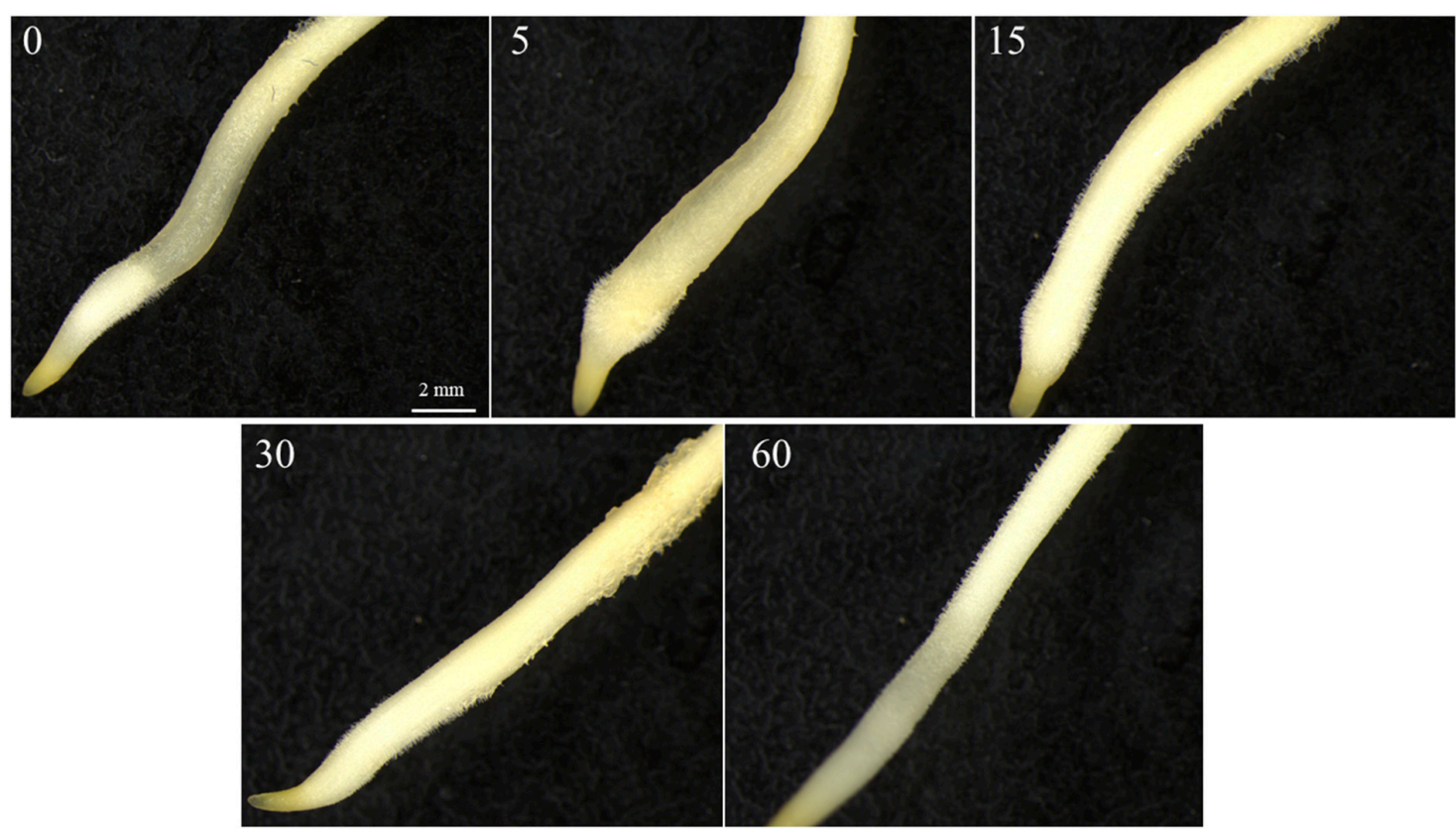

Figure 5. Detail showing the effect of $100 \mu \mathrm{mol} \mathrm{m} \mathrm{m}^{-2} \mathrm{~s}^{-1}$ red light exposure (0-60 min) of pea seeds on the development of root hairs of 3-day-old seedlings. Pictures were taking using a Leica MZ10 F modular stereo microscope with a $20 \times$ magnification. 

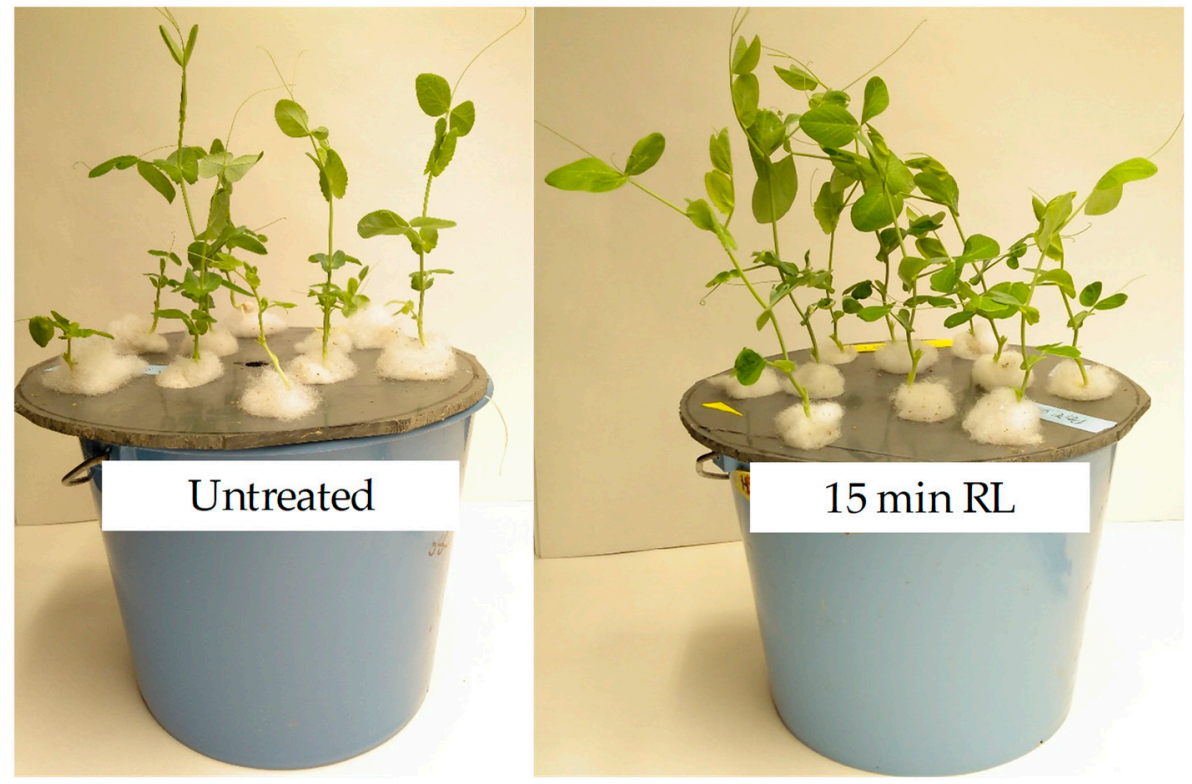

Figure 6. Image of 3-week-old pea plants after $15 \mathrm{~min}$ red light treatment of the seeds. Ten seedlings were transferred per pot and maintained in Hoagland's solution.

In order to assay the influence of RL on the antioxidative metabolism of the pea and melon seedlings, the main antioxidant enzymes activities (APX, SOD, POX, GR, MDHAR and DHAR) were determined on samples of untreated (as representative of control conditions), 15-min RL-treated seedlings (as growth-enhancing treatment for both melon and pea), and 30- and 60-min RL-treated seedlings (Figure 7).

Significant differences were only observed on melon samples, whereas values for all enzymes measured on pea seedlings remained unchanged. In melon, POX activity showed its highest value on untreated samples, whereas 15- and 30-min RL-treated samples showed $51 \%$ and $65 \%$ decreases, respectively $(p=0.019)$ (Figure 7a). SOD was higher on 15-min RL-treated samples with respect to untreated and 30-min RL-treated melon samples $(p=0.008)$ (Figure $7 \mathrm{~b})$. Regarding the ascorbate-glutathione (ASC-GSH) cycle enzymes, APX ( $p=0.049)$ and GR $(p=0.041)$ activities were lower on 15-min RL-treated samples with respect to untreated melon seedlings, the differences being $33 \%$ and $29 \%$, respectively (Figure $7 \mathrm{c}-\mathrm{d}$ ). On the other hand, MDHAR did not provide significant differences among samples $(p=0.165)$ (Figure 7e), and DHAR was not detectable either on melon or pea samples under our experimental conditions. 


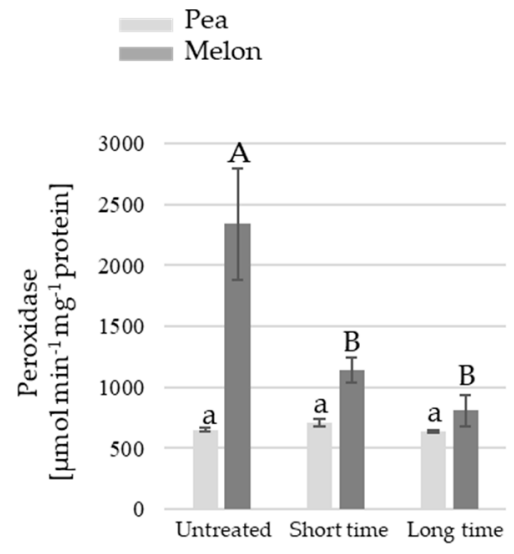

(a)

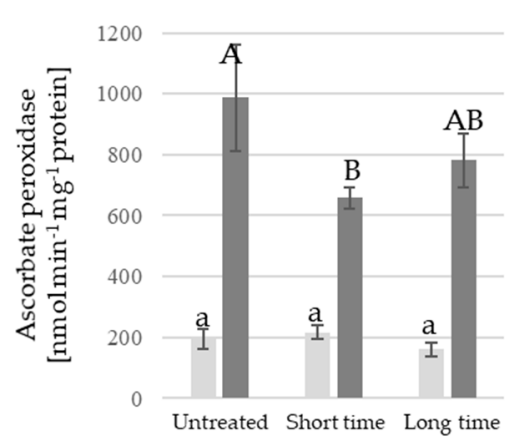

(c)

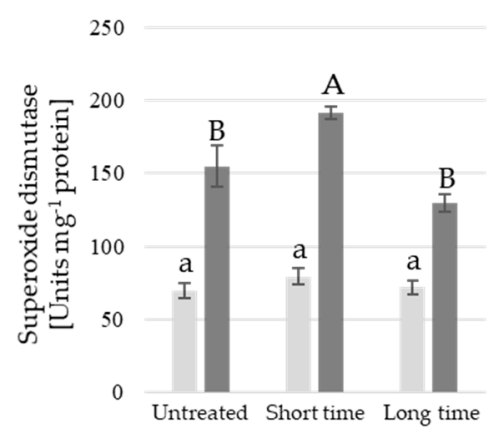

(b)

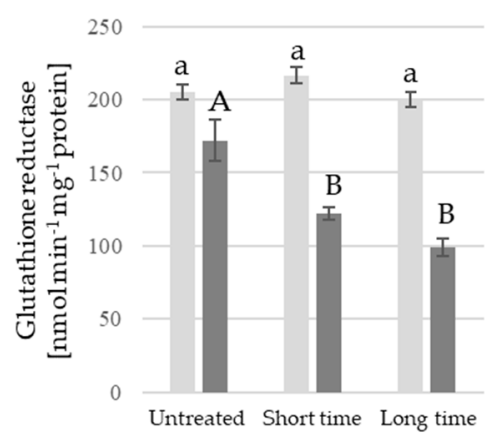

(d)

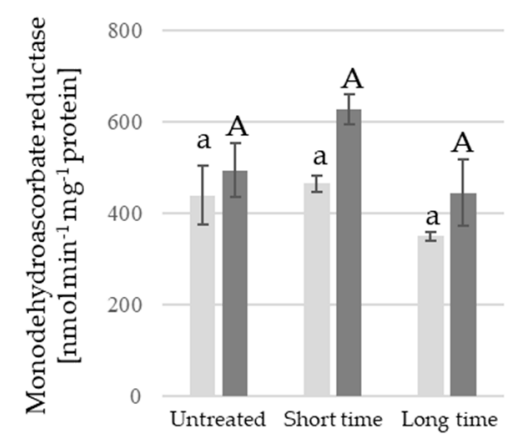

(e)

Figure 7. Activity of peroxidase (a), superoxide dismutase (b), ascorbate peroxidase (c), glutathione reductase (d) and monodehydroascorbate reductase (e) on samples of untreated, 15-min red light-treated (short time), and 30- and 60-min red light-treated seedlings (long time) for melon and pea, respectively. Data represent the mean \pm SE from 3 biological replicates, each one comprising all seedlings of a Petri dish. Different letters (small letters for pea and capital letters for melon) indicate significant differences according to Tukey's test $(p \leq 0.05)$.

\section{Discussion}

Most of the research concerning the effect of LED technology on plant growth and morphogenesis has been carried out under in vitro conditions [26]. However, the effects of LED lighting on seed germination and early seedling growth under ex vitro conditions have scarcely been documented. In the present study, a stimulating growth effect of monochromatic RL is demonstrated for the first time on pea and melon seedlings. 
Since plant photoreceptors are mainly stimulated by red and blue light spectra, the majority of in vitro studies have focused on evaluating the impact of monochromatic and mixed blue (440-480 nm) and red (640-670 nm) LED treatments. In this sense, the combination of red and blue LED light increased plant growth as well as the net photosynthetic rate of in vitro chrysanthemum plantlets, whereas the elongation of stem and internode length were higher under red LED light [34]. In other studies, the root formation of in vitro Anthurium plantlets was progressively induced under red LED lights [35]. Here, the exposure of melon and pea seeds to RL did not alter the germination percentage but significantly improved the early growth of the seedlings. This effect was dependent on the time of exposure to RL. In addition, RL exposure improved the root architecture, as seen by the increased volume of root hairs in both species. In this sense, increased root hairs can be a key point on facilitating seedling growth rate, as they have an important physical function in water absorption and nutrition [36]. Phytochromes have been reported to regulate the red light-mediated elongation of the primary root [37]. Moreover, their role in regulating lateral root production has been shown [38]. Thus, in this study, a link between RL and phytochrome activation could explain the enhanced hair root content and seedling growth.

Far-red light is known to inhibit seed germination by converting the existing pool of phytochrome into its inactive form [11-14]. However, the effect of long RL pulse as inhibitors of germination is less reported. In this work, 30- and 60-min RL irradiation did not increase seedling growth in melon and pea, respectively, in contrast to the effect of 15-min RL treatment. This might be attributed to a stress associated to an excess of irradiation, which in turns would mitigate the positive effects of the RL on seedling growth. In fact, in addition to its involvement on plant morphogenesis, LED irradiation also significantly alters the cellular redox balance. LED-induced changes in the generation of ROS and subsequent involvement of antioxidative enzyme activities have also been reported [26,27,39].

An imbalance of certain antioxidant enzymes was observed in 3-day-old melon seedlings. Fifteen-minute RL-treatment solely induced SOD $\left(\mathrm{H}_{2} \mathrm{O}_{2}\right.$-generating enzyme), whereas POX and APX $\left(\mathrm{H}_{2} \mathrm{O}_{2}\right.$-scavenging enzymes) were reduced. As a consequence, increased $\mathrm{H}_{2} \mathrm{O}_{2}$ accumulation can occur. This can be related to a controlled oxidative stress, leading to enhanced growth and root hairs of the melon seedlings. On the other hand, none of the activities showed significant changes on pea seedlings upon RL treatment. This could be explained by the timing of the treatment: a hypothetical initial oxidative stress during germination and early growth could induce an earlier activation of the antioxidant defenses, which-by the time the seedlings were analyzed, i.e., 3 days after light treatment-would have recovered their normal levels. It is interesting to notice that in both melon and pea seedlings, DHAR activity was undetectable. This response implies that ascorbate can be recycled by the MDHAR pathway, which uses NADPH as reducing power, which is much more efficient from an energy point of view, instead of the DHAR pathway, which uses GSH as electron donor [40].

Over the past decade, progresses in energy-efficient LED technology have been achieved. However, there is a need for independent data on how different lamps perform. Here, we report a low-energy consuming light chamber that can be used to improve the seed vigor of melon and pea, which could be relevant for growers as seed priming treatments. Further research is needed to understand the influence of RL LED waveband on ROS and antioxidant systems during germination and early plant growth, which might be a key point for enhancing the productivity of many economically important plants.

Author Contributions: Conceptualization, C.J.S., J.A.H., J.S. and G.B.-E.; Formal analysis, J.A.H. and G.B.-E.; Methodology, C.J.S., J.A.H., J.S. and G.B.-E.; Software, C.J.S. and J.S.; Supervision, J.A.H., J.S. and G.B.-E.; Writing-original draft, G.B.-E.; Writing—review and editing, C.J.S., J.A.H. and J.S. All authors have read and agreed to the published version of the manuscript.

Funding: This research was funded by the "Fundación Séneca"-Agency of Science and Technology of the Region of Murcia, grant number 20405/SF/17.

Conflicts of Interest: The authors declare no conflict of interest. 


\section{References}

1. Joosen, R.V.L.; Arends, D.; Li, Y.; Willems, L.A.J.; Keurentjes, J.J.B.; Ligterink, W.; Jansen, R.C.; Hilhorst, H.W.M. Identifying Genotype-by-Environment Interactions in the Metabolism of Germinating Arabidopsis Seeds Using Generalized Genetical Genomics. Plant Phys. 2013, 162, 553-566. [CrossRef]

2. Rosental, L.; Nonogaki, H.; Fait, A. Activation and regulation of primary metabolism during seed germination. Seed Sci. Res. 2014, 24,1-15. [CrossRef]

3. Donohue, K. Germination timing influences natural selection on life-history characters in Arabidopsis thaliana. Ecology 2002, 83, 1006-1016. [CrossRef]

4. Stutte, G.W. Light-emitting Diodes for Manipulating the Phytochrome Apparatus. HortScience 2009, 44, 231-234. [CrossRef]

5. Bae, G.; Choi, G. Decoding of light signals by plant phytochromes and their interacting proteins. Annu. Rev. Plant Biol. 2008, 59, 281-311. [CrossRef] [PubMed]

6. Grubišić, D.; Konjević, R. Light and nitrate interaction in phytochrome-controlled germination of Paulownia tomentosa seeds. Planta 1990, 181, 239-243. [CrossRef] [PubMed]

7. Lymperopoulos, P.; Msanne, J.; Rabara, R. Phytochrome and Phytohormones: Working in Tandem for Plant Growth and Development. Front. Plant Sci. 2018, 9, 1037. [CrossRef] [PubMed]

8. Mancinelli, A.L.; Borthwick, H.A. Photocontrol of germination and phytochrome reaction in dark-germinating seeds of Lactuca sativa L. Ann. Bot. 1964, 28, 9-24.

9. Devlin, P. Plants wait for the lights to change to red. PNAS 2016, 113, 7301-7303. [CrossRef]

10. Barba-Espín, G.; Díaz-Vivancos, P.; Clemente-Moreno, M.J.; Albacete, A.; Faize, L.; Faize, M.; Pérez-Alfocea, F.; Hernández, J.A. Interaction between hydrogen peroxide and plant hormones during germination and the early growth of pea seedlings. Plant Cell Environ. 2010, 33, 981-994. [CrossRef]

11. Ibarra, S.E.; Auge, G.; Sánchez, R.A.; Botto, J.F. Transcriptional Programs Related to Phytochrome A Function in Arabidopsis Seed Germination. Mol. Plant. 2013, 6, 1261-1273. [CrossRef] [PubMed]

12. Neff, M.M.; Sanderson, L.; Tedor, D. Light-Mediated Germination in Lettuce Seeds: Resurrection of a Classic Plant Physiology Lab Exercise. Am. Biol. Teach. 2009, 71, 367-370. [CrossRef]

13. Cresswell, E.G.; Grime, J.P. Induction of a light during seed development and its ecological consequences. Nature 1981, 291, 583-585. [CrossRef]

14. Salisbury, F.B.; Ross, C.W. Plant Physiology, 4th ed.; Wadsworth Publishing: Belmont, CA, USA, 1992.

15. Bradford, K.J.; May, D.M.; Hoyle, B.J.; Skibinski, Z.S.; Scott, S.J.; Tyler, K.B. Seed and Soil Treatments to Improve Emergence of Muskmelon from Cold or Crusted Soils. Crop. Sci. 1988, 28, 1001-1005. [CrossRef]

16. Nerson, H.; Govers, A. Salt priming of muskmelon seeds for low-temperature germination. Sci. Hortic. 1986, 28, 85-91. [CrossRef]

17. Sivritepe, H.Ö.; Sivritepe, N.; Eriş, A.; Turhan, E. The effects of $\mathrm{NaCl}$ pre-treatments on salt tolerance of melons grown under long-term salinity. Sci. Hortic. 2005, 106, 568-581. [CrossRef]

18. Yeoung, Y.R.; Wilson, D.O.; Murray, G.A. Germination performance and loss of late-embryogenesis-abundant (LEA) proteins during muskmelon seed priming. Seed Sci. Technol. 1996, 24, 429-439.

19. Gupta, S.D.; Jatothu, B. Fundamentals and applications of light-emitting diodes (LEDs) in in vitro plant growth and morphogenesis. Plant Biotechnol. Rep. 2013, 7, 211-220. [CrossRef]

20. Jones, M.A. Using light to improve commercial value. Hortic. Res. 2018, 5, 47. [CrossRef]

21. Matsuda, R.; Ohashi-Kaneko, K.; Fujiwara, K.; Goto, E.; Kurata, K. Photosynthetic Characteristics of Rice Leaves Grown under Red Light with or without Supplemental Blue Light. Plant Cell Physiol. 2004, 45, 1870-1874. [CrossRef]

22. Muleo, R.; Morini, S.; Casano, S. Photoregulation of growth and branching of plum shoots: Physiological action of two photosystems. In Vitro Cell. Dev. Biol.-Plant. 2001, 37, 609-617. [CrossRef]

23. Jing, X.; Wang, H.; Gong, B.; Liu, S.; Wei, M.; Ai, X.; Li, Y.; Shi, Q. Secondary and sucrose metabolism regulated by different light quality combinations involved in melon tolerance to powdery mildew. Plant Physiol. Biochem. 2018, 124, 77-87. [CrossRef]

24. Vidal, A.; Cantabella, D.; Bernal-Vicente, A.; Díaz-Vivancos, P.; Hernández, J.A. Nitrate- and nitric oxide-induced plant growth in pea seedlings is linked to antioxidative metabolism and the ABA/GA balance. J. Plant Physiol. 2018, 230, 13-20. [CrossRef] [PubMed] 
25. Agarwal, A.; Gupta, S.D. Impact of Light-Emitting Diodes (LEDs) and its Potential on Plant Growth and Development in Controlled-Environment Plant Production System. Curr. Biotechnol. 2016, 5, $28-43$. [CrossRef]

26. Gupta, S.D.; Agarwal, A. Influence of LED Lighting on In Vitro Plant Regeneration and Associated Cellular Redox Balance. In Light Emitting Diodes for Agriculture; Springer Nature: Singapore, 2017; pp. 273-303.

27. Benson, E.E. Do free radicals have a role in plant tissue culture recalcitrance? In Vitro Cell. Dev. Biol.-Plant 2002, 36, 163-170. [CrossRef]

28. Gechev, T.S.; Hille, J. Hydrogen peroxide as a signal controlling plant programmed cell death. J. Cell. Biol. 2005, 168, 17-20. [CrossRef]

29. Acosta-Motos, J.R.; Hernández, J.A.; Álvarez, S.; Barba-Espín, G.; Sánchez-Blanco, M.J. The long-term resistance mechanisms, critical irrigation threshold and relief capacity shown by Eugenia myrtifolia plants in response to saline reclaimed water. Plant Physiol. Biochem. 2017, 111, 244-256. [CrossRef]

30. Barba-Espin, G.; Nicolás, E.; Almansa, M.S.; Cantero-Navarro, E.; Albacete, A.; Hernández, J.A.; Díaz-Vivancos, P. Role of thioproline on seed germination: Interaction ROS-ABA and effects on antioxidative metabolism. Plant Physiol. Biochem. 2012, 59, 30-36. [CrossRef]

31. Bradford, M.M. A rapid and sensitive method for the quantitation of microgram quantities of protein utilizing the principle of protein-dye binding. Anal. Biochem. 1976, 7, 248-254. [CrossRef]

32. Barba-Espín, G.; Díaz-Vivancos, P.; Job, D.; Belghazi, M.; Job, C.; Hernández, J.A. Understanding the role of $\mathrm{H}_{2} \mathrm{O}_{2}$ during pea seed germination: A combined proteomic and hormone profiling approach. Plant Cell Environ. 2011, 34, 1907-1919. [CrossRef]

33. Hernández, J.A.; Jiménez, A.; Mullineaux, P.; Sevilla, F. Tolerance of pea (Pisum sativum L.) to long-term salt stress is associated with induction of antioxidant defences. Plant Cell Environ. 2000, 23, 862. [CrossRef]

34. Kim, S.J.; Hahn, E.J.; Heo, J.W.; Paek, K.Y. Effects of LEDs on net photosynthetic rate, growth and leaf stomata of chrysanthemum plantlets in vitro. Sci. Hortic. 2004, 101, 143-151. [CrossRef]

35. Kurniawan, B. Spectral quality affects morphogenesis on Anthurium plantlet during in vitro culture. Agrivita 2010, 32, 234-240.

36. Choi, H.; Cho, H. Root hairs enhance Arabidopsis seedling survival upon soil disruption. Sci. Rep. 2019, 9, 11181. [CrossRef] [PubMed]

37. Correll, M.J.; Kiss, J.Z. The roles of phytochromes in elongation and gravitropism of roots. Plant Cell Physiol. 2005, 46, 317-323. [CrossRef] [PubMed]

38. Salisbury, F.J.; Hall, A.; Grierson, C.S.; Halliday, K.J. Phytochrome coordinates Arabidopsis shoot and root development. Plant J. 2007, 50, 429-438. [CrossRef]

39. Bat'ková, P.; Pospíšilová, J.; Synková, H. Production of reactive oxygen species and development of antioxidative systems during in vitro growth and ex vitro transfer. Biol. Plant. 2008, 52, 413-422. [CrossRef]

40. Acosta-Motos, J.R.; Noguera-Vera, L.; Barba-Espín, G.; Piqueras, A.; Hernández, J.A. Antioxidant metabolism and chlorophyll fluorescence during the acclimatisation to ex vitro conditions of micropropagated Stevia rebaudiana Bertoni plants. Antioxidants 2019, 8, 615. [CrossRef]

(C) 2020 by the authors. Licensee MDPI, Basel, Switzerland. This article is an open access article distributed under the terms and conditions of the Creative Commons Attribution (CC BY) license (http://creativecommons.org/licenses/by/4.0/). 